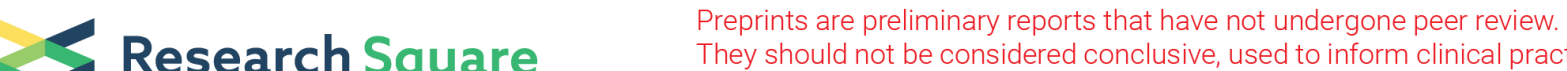 \\ They should not be considered conclusive, used to inform clinical practice, or referenced by the media as validated information.
}

\section{Evaluating the Association Between Physical Activity and Neuroticism in UK Biobank Cohort}

Peilin Meng

Xi'an Jiaotong University https://orcid.org/0000-0001-6297-0860

\section{Bolun Cheng}

Xi'an Jiaotong University

\section{Cuiyan Wu}

Xi'an Jiaotong University

Jing Ye

Xi'an Jiaotong University

Shiqiang Cheng

Xi'an Jiaotong University

Li Liu

Xi'an Jiaotong University

Chujun Liang

Xi'an Jiaotong University

Xuena Yang

Xi'an Jiaotong University

Xiaomeng Chu

Xi'an Jiaotong University

Yao Yao

Xi'an Jiaotong University

Chun'e Li

Xi'an Jiaotong University

Zhen Zhang

Xi'an Jiaotong University

\section{Yujing Chen}

Xi'an Jiaotong University

Chujun Pan

Xi'an Jiaotong University

Jingxi Zhang

Xi'an Jiaotong University

Huijie Zhang

Xi'an Jiaotong University

Yan Wen 
Xi'an Jiaotong University

\section{Sen Wang}

Xi'an Jiaotong University

Xi Wang

Xi'an Jiaotong University

\section{Yujie Ning}

Xi'an Jiaotong University

\section{Yumeng Jia}

Xi'an Jiaotong University

Feng Zhang ( $\nabla$ fzhxjtu@mail.xjtu.edu.cn )

Xi'an Jiaotong University https://orcid.org/0000-0003-1339-5956

\section{Research}

Keywords: physical activity, neuroticism, linear regression, gene-environment interaction.

Posted Date: September 27th, 2021

DOl: https://doi.org/10.21203/rs.3.rs-910537/v1

License: (c) (7) This work is licensed under a Creative Commons Attribution 4.0 International License. Read Full License 


\section{Abstract}

Background: The association between physical activity (PA) and neuroticism has been established, but the genetic mechanism remains elusive now.

Methods: In this study, 362,421 participants from UK Biobank were used to explore the associations between PA and neuroticism, using linear regression analysis. PA was measured as excess metabolic equivalent (MET)-hours per week, assessed from a combination of walking and moderate and vigorous PA. The Gene-environment-wide interaction analyses (GEWIS) was conducted by PLINK2.0 to evaluate genexPA interacting effects on the risk of neuroticism. DAVID tool was then used to conduct gene ontology (GO) analysis of the observed PA-interacted genes.

Results: We observed negative association between PA and neuroticism in total sample $(b=-0.02$, $\left.P=9.02 \times 10^{-37}\right)$, female sample $\left(b=-0.02, P=5.74 \times 10^{-28}\right)$ and male sample $\left(b=-0.02, P=6.17 \times 10^{-14}\right)$. GEWIS revealed multiple significant genexPA interaction signals for neuroticism. 78 candidate genes were observed, such as ST18(rs76573348, $P=6.45 \times 10^{-16}$ ) खNRCAM ( $\mathrm{rs} 117655943, P=4.28 \times 10^{-11}$ ) and RBFOX3(rs113329299, $P=4.72 \times 10^{-10}$ ) in total group, SYT1(rs151016298, $P=1.56 \times 10^{-11}$ ), S100B(rs80199493, $\left.P=8.56 \times 10^{-11}\right)$ and MYT1(rs111360063, $\left.P=1.53 \times 10^{-10}\right)$ in female group, and NOTCH3 (rs184928292, $P=3.31 \times 10^{-17}$ ), SLC24A2 (rs62563282, $\left.P=9.56 \times 10^{-16}\right)$, CSMD1(rs73177368, $\left.P=2.11 \times 10^{-13}\right)$ in male group. $\mathrm{GO}$ enrichment analysis identified 15,11 and $38 \mathrm{GO}$ terms for total, female and male samples, such as synapse assembly $\left(P_{\text {total }}=1.37 \times 10^{-2}\right)$, calcium ion binding $\left(P_{\text {female }}=3.33 \times 10^{-2}\right)$ and learning or memory $\left(P_{\text {male }}=1.14 \times 10^{-2}\right)$.

Conclusion: This study suggested the influences of physical activity on neuroticism, and identified several neuroticism associated genes interacting with PA.

\section{Background}

Neuroticism is a stable personality trait, referring to individual difference in negative emotionality or negative affectivity responding to loss, frustration and threat, which is defined by items concerning worry, anger, irritability, sadness, anxiety, hostility, vulnerability, and self-consciousness $(1)^{1}$. Public health research and mental health care use should attach more importance to neuroticism. High neuroticism is an established predictor of a widely range of mental and physical health problem( $(2)^{2}$, such as depression, atopic eczema, disrupted immune function, abnormalities in cardiac functioning, asthma and irritable bowel syndrome, even the increased risk of premature mortality. Besides, economic costs of neuroticism are enormous and exceed those of common mental disorders $(3)^{3}$. Its influence also robustly reflected in the life quality, such as lower well-being in later life $(4)^{4}$.

Previous studies demonstrated that genetic factors play an indispensable role in development of neuroticism. Twin and family studies indicated the moderate heritability of neuroticism could attribute approximately $40 \%$ of individual differences in the trait to genetic influences $(5)^{5}$. A meta-analysis 
including 29,496 twin pairs also demonstrated that the heritability of IRT-based scores for Neuroticism were $48 \%(6)^{6}$. A large GWAS meta-analysis in 449,484 individuals identified 136 independent genomewide significant loci for neuroticism $(7)^{7}$. Nonetheless, limited efforts in current research were paid to uncover the genetic mechanism of neuroticism.

Physical activity (PA), by definition, is any body movement which results in energy consumption, producing by skeletal muscular action $(8)^{8}$. The correlation of physical activity with health benefits and personality has been well-established (9) ${ }^{9}$. Regular moderate PA contributes to relieve the negative effects induced by age-related changes. Besides, regular PA was considered as a therapeutic intervention for prevent, treatment and management of chronic conditions and mental disorders $(10)^{10}$. Nevertheless, it's alarming that there are worldwide trends in physical inactivity among a multitude of adults $(11)^{11}$. The previous evidences demonstrated that personality traits might sharp various health behaviors, including $\mathrm{PA}(12)^{12}$. Several meta-analyses and reviews manifested that adults with high score in neuroticism tended to engage in more behaviors without body movement $(12-14)^{12-14}$. Recently, a cross-sectional analysis about accelerometer-measured and self-reported PA in relation to extraversion and neuroticism further found that neuroticism was related with lower leisure-time PA levels among middle-aged women $(15)^{15}$. However, the underlying genetic mechanism between PA and personality remains unclear.

It's known that most common and complex diseases are affected by the interaction between genes and environmental factors $(16)^{16}$. Gene-environment $(G \times E)$ interaction can potentially uncover the missing heritability problem $(17,18)^{17,18}$. Gene-environment-wide interaction analyses (GEWIS) is based on regression models involving G×E interaction(19) ${ }^{19}$. For instance, GEWIS of depressive symptoms and psychosocial stress in two UK population-based cohorts detected MTNR1B with G×E effect with dependent SLE in Generation Scotland; and PHF2 with the joint effect in UK Biobank(20) ${ }^{20}$. Understanding the relationship between gene polymorphism and environmental exposure can help to identify high-risk subgroups in the population and better understand the biological mechanisms of complex diseases(21) ${ }^{21}$.

In this study, UK Biobank cohort was adopted to assess the correlation between neuroticism and PA. GEWIS was then performed to evaluate the interaction effect of genexPA on the risk of neuroticism. Eventually, gene set enrichment analysis was conducted to detect biological pathways that contributing to the relationship between neuroticism and PA.

\section{Methods}

\section{Ethic statement}

This study has licensed from UK Biobank and got access to the individuals health-related record. Ethical approval of UK Biobank was granted by the National Health Service National Research Ethics Service (reference 11/NW/0382). 


\section{UK Biobank Samples}

Phenotypic data of PA and neuroticism in this study was derived from the UK Biobank (http://biobank.ndph. ox.ac.uk), which is a large and detailed prospective cohort study, enrolled over 500,000 volunteers cross England, Wales, and Scotland, aged 40-69 years in 2006-2010(22, 23) 22,23 .

\section{Phenotype definition of PA and neuroticism}

The excess metabolic equivalent (MET)-hours/week of PA was measured by an improved version of the International PA Questionnaire(24) ${ }^{24}$, including walking, moderate PA and vigorous PA preformed over last seven days. According to a standard scoring criteria, the participants were categorized as three mutually exclusive PA groups: low (<600 metabolic equivalent (MET)-min/week), moderate (600 to < $3000 \mathrm{MET}$-min/week), and high ( $\geq 3000 \mathrm{MET}-\mathrm{min} /$ week). Total MET values for each category were: 3.3 for walking, 4.0 for moderate PA and 8.0 for vigorous PA. The excess METs were calculated by subtracting one MET from the value for each activity, which representing the energy expenditure of an inactive individual $(25)^{25}$. For each category of PA, the duration of activity in hours per week were calculated by multiplying the number of reported days by the number of reported hours on a typical day. Accordingly, the excess MET-hours per week were generated from the product of the duration of activity in hours per week and the excess MET value for each activity.

Neuroticism was evaluated as a continuous trait using 12 questionnaire items from the Eysenck Personality Inventory Neuroticism scale (EPIN-R), such as "Are you often troubled by feelings of guilt?", "Would you call yourself a nervous person?" "Are your feelings easily hurt?" $(26)^{26}$. The answer of "Yes" and "No" were assign " 1 " and " 0 ", respectively. The scores were summed up to gain the total neuroticism score ranging from 0 to 12 where higher scores indicate higher neuroticism. The basic characteristics of study subjects are shown in Table 1. 
Table 1

List of top 10 neruoticism related candidate genes

\begin{tabular}{|c|c|c|c|}
\hline & SNP & Gene & $P$-value of interaction \\
\hline \multirow[t]{10}{*}{ Total sample } & rs76573348 & ST18 & $6.45 \times 10-16$ \\
\hline & rs149627836 & LOC105372663 & $7.70 \times 10-14$ \\
\hline & rs75125688 & LOC105374971 & $1.73 \times 10-13$ \\
\hline & rs1800892 & IL19 & $4.35 \times 10-13$ \\
\hline & rs74480956 & MYH9 & $1.93 \times 10-12$ \\
\hline & rs72952034 & SPAG16 & $2.31 \times 10-12$ \\
\hline & rs188969758 & WWOX & $9.70 \times 10-12$ \\
\hline & rs141894018 & LOC107986098 & $1.02 \times 10-11$ \\
\hline & rs76650499 & FCGRT & $2.05 \times 10-11$ \\
\hline & rs141550369 & LINC01250 & $2.70 \times 10-11$ \\
\hline \multirow[t]{10}{*}{ Female sample } & rs148872589 & NIBAN1 & $4.20 \times 10-14$ \\
\hline & rs 12712979 & MCFD2,TTC7A & $3.14 \times 10-13$ \\
\hline & rs 72737760 & LOC105371648 & $2.19 \times 10-12$ \\
\hline & rs189201233 & LOC643339,LOC105369907 & $4.35 \times 10-12$ \\
\hline & rs72762267 & LOC105370955 & $6.40 \times 10-12$ \\
\hline & rs 10744778 & NAA25 & $1.39 \times 10-11$ \\
\hline & rs151016298 & SYT1,LOC105369863 & $1.56 \times 10-11$ \\
\hline & rs139860747 & ARHGAP26 & $2.30 \times 10-11$ \\
\hline & rs140687130 & LOC643339,LINC02413 & $2.77 \times 10-11$ \\
\hline & rs148534983 & PTPN11 & $4.11 \times 10-11$ \\
\hline \multirow[t]{5}{*}{ Male sample } & rs144611731 & LOC101929762 & $1.13 \times 10-18$ \\
\hline & rs139211146 & MLLT1 & $2.82 \times 10-18$ \\
\hline & rs187340202 & FAM53A & $4.95 \times 10-18$ \\
\hline & rs184928292 & NOTCH3 & $3.31 \times 10-17$ \\
\hline & rs117531541 & PCDH15 & $1.24 \times 10-16$ \\
\hline
\end{tabular}

Abbreviation: SNP single nucleotide polymorphism. 


\begin{tabular}{|c|cll|}
\hline SNP & Gene & P-value of interaction \\
\hline rs117439512 & RAB27B & $2.82 \times 10-16$ \\
\hline rs112547094 & PALB2,DCTN5 & $5.72 \times 10-16$ \\
\hline rs62563282 & SLC24A2 & $9.56 \times 10-16$ \\
\hline rs13205743 & SLC2A12 & $1.26 \times 10-15$ \\
\hline rs147268023 & LOC105371413 & $1.53 \times 10-15$ \\
\hline Abbreviation: SNP single nucleotide polymorphism. & \\
Genotyping, imputation, and quality control
\end{tabular}

In brief, genotypes from a total of 488,377 participants were processed by either the UK Bileve array or the UK Biobank axiom array. Detailed information about array design, genotyping, and quality control procedures have been described in previous studies $(27)^{27}$. Notably, $95 \%$ of marker content were shared in these two arrays. Subsequently, based on Haplotype Reference Consortium (HRC) reference panel19 (version1.1) and UK10K and 1000 Genomes project reference panels, these genotype results were used to make imputation. Additionally, the participants with gender mismatch, missingness, relatedness, nonBritish ancestry were removed. An estimator implemented in the KING software was used to obtained the relatively independent single nucleotide polymorphism (SNP).

\section{Linear regression model}

Association analyses of PA and neuroticism were tested using a linear regression model by R software (version 3.5.3), PA was used as instrument variable in regression analysis, while neuroticism was used as outcome variables. The age, sex, and 10 principle components of population structure were used as covariates.

\section{Gene-environment-wide interaction analyses}

The GEWIS was conducted to estimate the association between genetic factors and PA for neuroticism, which is more powerful to detect the associations between genetic variant and complex diseases. The generalized linear regression model of PLINK2.0 $(28,29)^{28,29}$ was performed using gender, age, and the first 10 European-specific principal components as covariates. The genetic additive (ADD) and dominance (DOM) models of PLINK2.0 were applied as the previous study described $(30,31)^{30,31}$. For $Q C$, the low call rates of $S N P<0.90$, Hardy-Weinberg equilibrium exact test $P$ values $<0.001$, or minor allele frequencies $<0.01$ were excluded $(32)^{32}$. The Manhattan plots were generated using "CMplot" package (https://github.com/YinLiLin/R-CMplot) in R platform. Significant SNPs for G×E effects were identified at a genome-wide significance threshold of $P$ value $<1.0 \times 10^{-8}$.

\section{Gene set enrichment analyses}


Database for Annotation, Visualization and Integrated Discovery (DAVID, https://david.ncifcrf.gov), a bioinformatics resources, which is consists of an integrated biological knowledgebase and analytic tools $(33)^{33}$. It was designed to systematically extract biological meaning from large gene or protein lists $(34)^{34}$. In this study, DAVID was applied to conduct the Gene Ontology (GO) and pathway enrichment analyses of the GEWIS results to explore the functional relevance of identified genes interacting with PA. Only terms with $P<0.05$ were considered as cut-off criterion.

\section{Results}

\section{Characteristics of study subjects from UK Biobank}

362,421 samples were recruited in this study (the mean age was $56.36 \pm 8.09$ years old), including 170,431 male samples (the mean age was $56.66 \pm 8.18$ years old) and 191,990 female samples (the mean age was $56.09 \pm 8.00$ years old).

\section{Association between neuroticism and physical activity}

In UK Biobank cohort, the negative association between neuroticism and physical activity was observed in the total sample $\left(b=-0.02, P=9.02 \times 10^{-37}\right)$, such association also was observed in the female sample $\left(b=-0.02, P=5.74 \times 10^{-28}\right)$ and male sample $\left(b=-0.02, P=6.17 \times 10^{-14}\right)$.

\section{Gene-environment-wide interaction analyses results}

For total samples, 78 candidate genes interacting with PA were detected for neuroticism, such as ST18 (rs76573348, $P=6.45 \times 10^{-16}$ ), NRCAM (rs117655943, $P=4.28 \times 10^{-11}$ ) and RBFOX3(rs113329299, $P=$ $4.72 \times 10^{-10}$ ) (Fig. 1.a). For female group, there were 91 candidate gene $\times$ PA interactions, such as SYT1 (rs151016298, $\left.P=1.56 \times 10^{-11}\right), \mathrm{S} 100 \mathrm{~B}\left(\mathrm{rs} 80199493, P=8.56 \times 10^{-11}\right.$ ) and MYT1 (rs111360063, $P=$ $1.53 \times 10^{-10}$ ) (Fig. 1.b). For male group, multiple candidate genes were observed to interact with PA, such as NOTCH3 (rs184928292, $\left.P=3.31 \times 10^{-17}\right)$, SLC24A2 (rs62563282, $\left.P=9.56 \times 10^{-16}\right)$ and CSMD1 (rs73177368, $P=2.11 \times 10^{-13}$ ) (Fig. 1.c). Top 10 candidate genes for each group were listed in Table 1, and more detailed information was shown in Supplementary Tables 1-3. Notably, KCNIP4 was detected in both total and female group; CCSER1, NKAIN2, PTPRT were shared in total sample and male group; LINC02641 was common in female and male groups.

\section{Gene set enrichment analysis}

For total sample, we observed $15 \mathrm{GO}$ terms, such as presynapse (G0:0098793, $P=1.33 \times 10^{-2}$ ), synapse assembly (G0:0007416, $P=1.37 \times 10^{-2}$ ), and neuron cell-cell adhesion (G0:0007158, $P=4.57 \times 10^{-2}$ ). For female sample, we detected $11 \mathrm{GO}$ terms,such as calcium ion binding (G0:0005509, $\left.P=3.33 \times 10^{-2}\right)$. For male sample, we identified $38 \mathrm{GO}$ terms, for instance, learning or memory (GO:0007611, $P=1.14 \times 10^{-2}$ ), 
neuron projection (GO:0043005, $P=1.68 \times 10^{-2}$ ). The top $10 \mathrm{GO}$ terms for each sample are shown in Table 2. Zinc ion binding (G0:0008270) was overlapped in the male and female groups. 
Table 2

List of top 10 neuroticism-associated GO terms

\begin{tabular}{|c|c|c|c|c|}
\hline & Category & Term ID & Term descriptions & $P$-Value \\
\hline \multirow[t]{10}{*}{$\begin{array}{l}\text { Total } \\
\text { sample }\end{array}$} & $\mathrm{BP}$ & GO:1901796 & $\begin{array}{l}\text { regulation of signal transduction by p } 53 \text { class } \\
\text { mediator }\end{array}$ & $\begin{array}{l}5.65 \times 10^{-} \\
3\end{array}$ \\
\hline & BP & GO:0060760 & $\begin{array}{l}\text { positive regulation of response to cytokine } \\
\text { stimulus }\end{array}$ & $\begin{array}{l}5.83 \times 10^{-} \\
3\end{array}$ \\
\hline & $\mathrm{BP}$ & GO:0071560 & $\begin{array}{l}\text { cellular response to transforming growth factor } \\
\text { beta stimulus }\end{array}$ & $\begin{array}{l}8.99 \times 10^{-} \\
3\end{array}$ \\
\hline & $\mathrm{CC}$ & GO:0098793 & presynapse & $\begin{array}{l}1.33 \times 10^{-} \\
2\end{array}$ \\
\hline & $\mathrm{BP}$ & GO:0007416 & synapse assembly & $\begin{array}{l}1.37 \times 10^{-} \\
2\end{array}$ \\
\hline & $\mathrm{CC}$ & G0:0043231 & intracellular membrane-bounded organelle & $\begin{array}{l}1.80 \times 10^{-} \\
2\end{array}$ \\
\hline & $\mathrm{BP}$ & G0:0030334 & regulation of cell migration & $2^{1.97 \times 10^{-}}$ \\
\hline & MF & GO:0001075 & $\begin{array}{l}\text { transcription factor activity, RNA polymerase II } \\
\text { core promoter sequence-specific binding involved } \\
\text { in preinitiation complex assembly }\end{array}$ & $\begin{array}{l}2.58 \times 10^{-} \\
2\end{array}$ \\
\hline & $\mathrm{BP}$ & GO:0007494 & midgut development & $2.60 \times 10^{-}$ \\
\hline & $\mathrm{BP}$ & GO:0001525 & angiogenesis & $\begin{array}{l}2.72 \times 10^{-} \\
2\end{array}$ \\
\hline \multirow[t]{4}{*}{$\begin{array}{l}\text { Male } \\
\text { sample }\end{array}$} & BP & GO:0007220 & Notch receptor processing & $\begin{array}{l}1.36 \times 10^{-} \\
3\end{array}$ \\
\hline & $\mathrm{CC}$ & GO:0005887 & integral component of plasma membrane & $3^{1.90 \times 10^{-}}$ \\
\hline & $\mathrm{CC}$ & GO:0031512 & motile primary cilium & $\begin{array}{l}7.84 \times 10^{-} \\
3\end{array}$ \\
\hline & MF & GO:0035259 & glucocorticoid receptor binding & $\begin{array}{l}9.61 \times 10^{-} \\
3\end{array}$ \\
\hline $\begin{array}{l}\text { Abbrevi } \\
\text { Functior }\end{array}$ & n: GO ger & ontology, BP E & logical Processes, CC Cellular Components, MF M & ecular \\
\hline
\end{tabular}




\begin{tabular}{|c|c|c|c|c|}
\hline & Category & Term ID & Term descriptions & $P$-Value \\
\hline & $\mathrm{BP}$ & GO:0006874 & cellular calcium ion homeostasis & $\begin{array}{l}1.02 \times 10^{-} \\
2\end{array}$ \\
\hline & MF & GO:0005509 & calcium ion binding & $\begin{array}{l}1.07 \times 10^{-} \\
2\end{array}$ \\
\hline & $\mathrm{CC}$ & G0:0033017 & sarcoplasmic reticulum membrane & $\begin{array}{l}1.12 \times 10^{-} \\
-\end{array}$ \\
\hline & $\mathrm{BP}$ & Go:0007611 & learning or memory & $\begin{array}{l}1.41 \times 10^{-} \\
2\end{array}$ \\
\hline & MF & GO:0034236 & protein kinase $A$ catalytic subunit binding & $2^{1.55 \times 10^{-}}$ \\
\hline & $\mathrm{CC}$ & GO:0043005 & neuron projection & $\begin{array}{l}1.68 \times 10^{-} \\
-\end{array}$ \\
\hline $\begin{array}{l}\text { Female } \\
\text { sample }\end{array}$ & $\mathrm{CC}$ & GO:0005737 & cytoplasm & $\begin{array}{l}8.61 \times 10^{-} \\
3\end{array}$ \\
\hline & $\mathrm{BP}$ & GO:0061337 & cardiac conduction & $\begin{array}{l}1.09 \times 10^{-} \\
-\end{array}$ \\
\hline & MF & Go:0008270 & zinc ion binding & ${ }_{2}^{1.58 \times 10^{-}}$ \\
\hline & $\mathrm{BP}$ & GO:0006260 & DNA replication & $\begin{array}{l}1.72 \times 10^{-} \\
2\end{array}$ \\
\hline & $\mathrm{BP}$ & GO:0050790 & regulation of catalytic activity & $\begin{array}{l}2.25 \times 10^{-} \\
2\end{array}$ \\
\hline & BP & Go:0060119 & inner ear receptor cell development & $\begin{array}{l}2.43 \times 10^{-} \\
-\end{array}$ \\
\hline & MF & GO:0005509 & calcium ion binding & $\begin{array}{l}3.33 \times 10^{-} \\
2\end{array}$ \\
\hline & BP & GO:0007626 & locomotory behavior & $\begin{array}{l}3.52 \times 10^{-} \\
2\end{array}$ \\
\hline
\end{tabular}

Abbreviation: GO gene ontology, BP Biological Processes, CC Cellular Components, MF Molecular Functions. 


\begin{tabular}{|cclc|}
\hline Category & Term ID & Term descriptions & $P$-Value \\
\hline BP & G0:0007229 & integrin-mediated signaling pathway & $\begin{array}{l}4.74 \times 10^{-} \\
2\end{array}$ \\
\hline BP & G0:0006469 & negative regulation of protein kinase activity & $\begin{array}{l}4.74 \times 10^{-} \\
2\end{array}$ \\
\hline $\begin{array}{l}\text { Abbreviation: GO gene ontology, BP Biological Processes, CC Cellular Components, MF Molecular } \\
\text { Functions. }\end{array}$ & & \\
\hline
\end{tabular}

\section{Discussion}

Based on the large sample of middle-aged men and women, this study focused on the role of PA acted in the progression of neuroticism by conducting an observational study with GEWIS in UK Biobank cohort. We noticed a significant negative association between neuroticism and PA. GEWIS was performed to identify specific genex PA interactions for neuroticism.

The negative relationship between PA and mental health has been widely documented, and only in neurotic-introverts, higher levels of physical activity were associated with better mental health $(35)^{35}$. A case in point is that neuroticism negatively correlates with muscle strength which could be explain PA level $(36)^{36}$. What's more, Artese et al. found that neuroticism was inversely related to more moderate PA and steps per day in older adults(37) ${ }^{37}$. In our analysis, negative association has been established between neuroticism and PA in the population-based observational analysis.

The neuroticism with higher scores reflected an autonomic nervous system which was to slowly recover from reaction to stress, having greater activation levels and lower thresholds within subcortical structures $(38)^{38}$. Neuroanatomical studies have demonstrated that neuroticism was related to variations in the orbitofrontal cortex, precentral gyrus (PreCG), and amygdala (AMY) (39) ${ }^{39}$, which resulted in the manifestation of behavioral characteristics. GEWIS detected several critical candidate genes that may help to explain the relationship between neuroticism and PA. In total sample, neuronal cell adhesion molecule (NRCAM) has been verified to be involved in altering functional interactions in the orbitofrontal cortex and mediating the formation of ST axonal fibers, which was essential for normal amygdaloidBNST circuits and responses to background fear conditioning $(40,41)^{40,41}$. NRCAM acts a diverse part in neurite extension, its dysregulation is consistent with a synaptic abnormality, which provides potential molecular mechanism for certain neuropsychiatric disorders $(42)^{42}$. One important result of male sample in GEWIS is notch receptor 3(NOTCH3), a member of NOTCH receptors, has been identified as a critical regulator in maintenance and differentiation of adult $\mathrm{NSCs}(43)^{43}$. The abnormal expression of NOTCH3 in AMY was one of main cause of Cerebral autosomal dominant arteriopathy with subcortical infarcts (CADASIL) and suicidal victims $(44,45)^{44,45}$. Among gene candidates having biased expression in brain in female group, synaptotagmin 1 (SYT1) is of particular interest, which belongs to a family of 
synaptotagmins, modulating synaptic vesicle endocytosis and acting as an indispensable mediator of fast, synchronous, calcium-dependent neurotransmitter $(46)^{46}$. SYT1 hypothalamic knockdown prevents hippocampal neurons from AMY seizure-induced damage $(47)^{47}$. Given the fact that the important role of these genes as an outcome predictor and marker of neuroticism status, the relationship among PA, neuroticism and these genes deserves to be deeply explored. Further analyses are warranted to validate our results.

Gene set enrichment analysis also identified some GO terms related to synapse, neuron and axon, which affect neural development. A pathway-based meta-analysis indicated that underlying neurodevelopmental processes might be a common genetic component of lower-level neuroticism, and axon guidance pathway was associated with numerous facets of neuroticism $(48)^{48}$. Calcium ions mediate neural functions by transmitting depolarization signals and synaptic activity and play an essential role in the regulation of various neural processes $(49)^{49}$. In our study, calcium ion binding was detected in female group, which reinforced that calcium-related pathways possibly involving in the susceptibility to anxiety and mood disorders, and participating in self-regulation of negative emotions and psychological distress $(48)^{48}$.

The common genes and pathways among three groups could provide several important evidences for gender-specific expression. Sodium/potassium transporting ATPase interacting 2(NKAIN2) is highly expressed in brain tissue, and strongly associated with neurological phenotypes $(50)^{50}$, KAIN2 overlapped in the total sample and the male sample, suggesting that NKAIN2 was the main effect factor of neuroticism $(51)^{51}$. Protein tyrosine phosphatase receptor type T (PTPRT) expression is restricted to the nervous system and is a regulator of synaptic formation and neuron development $(52)^{52}$. Potassium voltage-gated channel interacting protein 4(KCNIP4) was significantly correlated in both total and female group, and was considered as the risk gene in personality disorders $(53)^{53}$. Interestingly, we observed that zinc ion binding was common in female and male samples. Zinc ion is an endogenous neuromodulator widely found in the central nervous system $(54)^{54}$, and its deficiency increases the risk of neurological disease $(55)^{55}$. We may infer that zinc-related pathways are potentially related to personal traits.

Certain limitations in present study should be noted. Firstly, all subjects in this study were collected from UK Biobank, considering the discrepancy of genetic background, it should be cautious to apply on other populations. Secondly, this study only focused on the middle-aged individual, which was hard to generalize whole lifespan. Thirdly, the MET-hours/week of PA and neuroticism was measured by questionnaires which are retrospective measurements, and may lead to the possibility of recall bias.

In conclusion, an observational study was conducted to explore the relationship between neuroticism and PA based on UK Biobank samples. GEWIS and pathway analysis provided substantial PA-based and common genetic effects on neuroticism. Underlying neurophysiological mechanisms play an important role for improving symptoms of neuroticism. Traditionally, pharmacological- and psychotherapy-based interventions have been considered for treating neuroticism, nevertheless, our results highlight the 
importance of healthy lifestyle for mental health and provide novel clues for the psychiatric disorder neurodegenerative disease management. Considering the benefits of regular PA for the prevention of neuroticism and the promotion psychological well-being, it seems to be an effective therapeutic approach with low cost that should be integrated into clinical practice.

\section{Declarations}

\section{Ethics approval and consent to participate}

There is no ethical statement here, because of all data downloaded from the

Internet.

\section{Consent for publication}

There is no consent for publication here, because of all data downloaded from the

Internet.

\section{Availability of data and materials}

The datasets analyzed in this article are not publicly available. Requests to access the datasets should be directed to fzxjtu@mail.xjtu.edu.cn.

\section{Competing interests}

All authors declared that they have no conflicts of interest to this work.

\section{Funding}

This study is supported by the National Natural Scientific Foundation of China (grant number:81922059).

\section{Authors' contributions}

Meng and Cheng drafted the manuscript. Zhang designed the study. Ye, Yang, Liang, Chu, Cheng Wu, Zhang and Wang performed the statistical analyses. Yao, Li, Zhang, Pan, Chen, Zhang, Wen, Wang, Zhang, Jia囚Guo, and Ning provided feasible advice on data analysis and drafting manuscript. All authors read and approved the final manuscript. All authors discussed the results and commented on the manuscript.

\section{Acknowledgements}

This research has been conducted using the UK Biobank Resource. 


\section{References}

1. Goldberg LR. The structure of phenotypic personality traits. The American psychologist. 1993;48(1):2634.

2. Lahey BB. Public health significance of neuroticism. The American psychologist. 2009;64(4):241-56.

3. Cuijpers P, Smit F, Penninx BW, de Graaf R, ten Have M, Beekman AT. Economic costs of neuroticism: a population-based study. Archives of general psychiatry. 2010;67(10):1086-93.

4. Lehto K, Karlsson I, Lundholm C, Pedersen NL. Genetic risk for neuroticism predicts emotional health depending on childhood adversity. Psychological medicine. 2019;49(2):260-7.

5. Vukasović T, Bratko D. Heritability of personality: A meta-analysis of behavior genetic studies. Psychological bulletin. 2015;141(4):769-85.

6. van den Berg SM, de Moor MH, McGue M, Pettersson E, Terracciano A, Verweij KJ, et al. Harmonization of Neuroticism and Extraversion phenotypes across inventories and cohorts in the Genetics of Personality Consortium: an application of Item Response Theory. Behavior genetics. 2014;44(4):295-313.

7. Nagel M, Jansen PR, Stringer S, Watanabe K, de Leeuw CA, Bryois J, et al. Meta-analysis of genomewide association studies for neuroticism in 449,484 individuals identifies novel genetic loci and pathways. Nature genetics. 2018;50(7):920-7.

8. Sharif K, Watad A, Bragazzi NL, Lichtbroun M, Amital H, Shoenfeld Y. Physical activity and autoimmune diseases: Get moving and manage the disease. Autoimmunity reviews. 2018;17(1):53-72.

9. Allen MS, Laborde SJCDiPe. The Role of Personality in Sport and Physical Activity. 2014;23(6):692\&ndash;700.

10. Chodzko-Zajko WJ, Proctor DN, Fiatarone Singh MA, Minson CT, Nigg CR, Salem GJ, et al. Exercise and Physical Activity for Older Adults. 2009;41(7):1510-30.

11. Guthold R, Stevens GA, Riley LM, Bull FC. Worldwide trends in insufficient physical activity from 2001 to 2016: a pooled analysis of 358 population-based surveys with 1.9 million participants. The Lancet Global health. 2018;6(10):e1077-e86.

12. Rhodes RE, Smith NE. Personality correlates of physical activity: a review and meta-analysis. British journal of sports medicine. 2006;40(12):958-65.

13. Wilson KE, Dishman RKJP, Differences I. Personality and physical activity: A systematic review and meta-analysis. 2015;72:230-42.

14. Sutin AR, Stephan Y, Luchetti M, Artese A, Oshio A, Terracciano A. The Five-Factor Model of Personality and Physical Inactivity: A Meta-Analysis of 16 Samples. Journal of research in personality. 
2016;63:22-8.

15. Kekäläinen T, Laakkonen EK, Terracciano A, Savikangas T, Hyvärinen M, Tammelin TH, et al. Accelerometer-measured and self-reported physical activity in relation to extraversion and neuroticism: a cross-sectional analysis of two studies. BMC geriatrics. 2020;20(1):264.

16. Manolio TA, Collins FS, Cox NJ, Goldstein DB, Hindorff LA, Hunter DJ, et al. Finding the missing heritability of complex diseases. Nature. 2009;461(7265):747-53.

17. Thomas D. Gene--environment-wide association studies: emerging approaches. Nature reviews Genetics. 2010;11(4):259-72.

18. Ober C, Vercelli D. Gene-environment interactions in human disease: nuisance or opportunity? Trends in genetics : TIG. 2011;27(3):107-15.

19. Ueki M, Fujii M, Tamiya G. Quick assessment for systematic test statistic inflation/deflation due to null model misspecifications in genome-wide environment interaction studies. PLoS One. 2019;14(7):e0219825.

20. Arnau-Soler A, Macdonald-Dunlop E, Adams MJ. Genome-wide by environment interaction studies of depressive symptoms and psychosocial stress in UK Biobank and Generation Scotland. 2019;9(1):14.

21. Murcray CE, Lewinger JP, Gauderman WJ. Gene-environment interaction in genome-wide association studies. American journal of epidemiology. 2009;169(2):219-26.

22. Ollier W, Sprosen T, Peakman T. UK Biobank: from concept to reality. Pharmacogenomics. 2005;6(6):639-46.

23. Sudlow C, Gallacher J, Allen N, Beral V, Burton P, Danesh J, et al. UK biobank: an open access resource for identifying the causes of a wide range of complex diseases of middle and old age. PLoS medicine. 2015;12(3):e1001779.

24. Fan M, Lyu J, He P. [Chinese guidelines for data processing and analysis concerning the International Physical Activity Questionnaire]. Zhonghua liu xing bing xue za zhi = Zhonghua liuxingbingxue zazhi. 2014;35(8):961-4.

25. Howley ET. Type of activity: resistance, aerobic and leisure versus occupational physical activity. Medicine and science in sports and exercise. 2001;33(6 Suppl):S364-9; discussion S419-20.

26. Smith DJ, Nicholl BI, Cullen B, Martin D, Ul-Haq Z, Evans J, et al. Prevalence and characteristics of probable major depression and bipolar disorder within UK biobank: cross-sectional study of 172,751 participants. PLoS One. 2013;8(11):e75362. 
27. Bycroft C, Freeman C, Petkova D, Band G, Elliott LT, Sharp K, et al. The UK Biobank resource with deep phenotyping and genomic data. Nature. 2018;562(7726):203-9.

28. Purcell S, Neale B, Todd-Brown K, Thomas L, Ferreira MA, Bender D, et al. PLINK: a tool set for wholegenome association and population-based linkage analyses. American journal of human genetics. 2007;81(3):559-75.

29. Kraft P, Yen YC, Stram DO, Morrison J, Gauderman WJ. Exploiting gene-environment interaction to detect genetic associations. Human heredity. 2007;63(2):111-9.

30. Rivera NV, Patasova K, Kullberg S, Diaz-Gallo LM, Iseda T, Bengtsson C, et al. A Gene-Environment Interaction Between Smoking and Gene polymorphisms Provides a High Risk of Two Subgroups of Sarcoidosis. 2019;9(1):18633.

31. Clarke GM, Morris AP. A comparison of sample size and power in case-only association studies of gene-environment interaction. American journal of epidemiology. 2010;171(4):498-505.

32. Chang CC, Chow CC, Tellier LC, Vattikuti S, Purcell SM, Lee JJ. Second-generation PLINK: rising to the challenge of larger and richer datasets. GigaScience. 2015;4:7.

33. Huang da W, Sherman BT, Lempicki RA. Systematic and integrative analysis of large gene lists using DAVID bioinformatics resources. Nature protocols. 2009;4(1):44-57.

34. Dennis G, Jr., Sherman BT, Hosack DA, Yang J, Gao W, Lane HC, et al. DAVID: Database for Annotation, Visualization, and Integrated Discovery. Genome biology. 2003;4(5):P3.

35. Wilson KE, Das BM, Evans EM, Dishman RK. Structural Equation Modeling Supports a Moderating Role of Personality in the Relationship Between Physical Activity and Mental Health in College Women. Journal of physical activity \& health. 2016;13(1):67-78.

36. Tolea MI, Terracciano A, Simonsick EM, Metter EJ, Costa PT, Jr., Ferrucci L. Associations between personality traits, physical activity level, and muscle strength. Journal of research in personality. 2012;46(3):264-70.

37. Artese A, Ehley D, Sutin AR, Terracciano A. Personality and actigraphy-measured physical activity in older adults. Psychology and aging. 2017;32(2):131-8.

38. Wei L, Duan X, Zheng C, Wang S, Gao Q, Zhang Z, et al. Specific frequency bands of amplitude lowfrequency oscillation encodes personality. Human brain mapping. 2014;35(1):331-9.

39. Deyoung CG. Personality Neuroscience and the Biology of Traits. Social \& Personality Psychology Compass. 2010;4(12):1165-80. 
40. Dixson L, Walter H, Schneider M, Erk S, Schäfer A, Haddad L, et al. Identification of gene ontologies linked to prefrontal-hippocampal functional coupling in the human brain. Proc Natl Acad Sci U S A. 2014;111(26):9657-62.

41. Mohan V, Gomez JR, Maness PF. Expression and Function of Neuron-Glia-Related Cell Adhesion Molecule (NrCAM) in the Amygdalar Pathway. Frontiers in cell and developmental biology. 2019;7:9.

42. Vawter MP. Dysregulation of the neural cell adhesion molecule and neuropsychiatric disorders. European journal of pharmacology. 2000;405(1-3):385-95.

43. Imayoshi I, Kageyama R. The role of Notch signaling in adult neurogenesis. Molecular neurobiology. 2011;44(1):7-12.

44. Dunphy L, Rani A, Duodu Y, Behnam Y. Cerebral autosomal dominant arteriopathy with subcortical infarcts and leucoencephalopathy (CADASIL) presenting with stroke in a young man. BMJ case reports. 2019;12(7).

45. Monsalve EM, García-Gutiérrez MS, Navarrete F, Giner S, Laborda J, Manzanares J. Abnormal Expression Pattern of Notch Receptors, Ligands, and Downstream Effectors in the Dorsolateral Prefrontal Cortex and Amygdala of Suicidal Victims. Molecular neurobiology. 2014;49(2):957-65.

46. Baker K, Gordon SL, Melland H, Bumbak F, Scott DJ, Jiang TJ, et al. SYT1-associated neurodevelopmental disorder: a case series. Brain : a journal of neurology. 2018;141(9):2576-91.

47. Kobayashi S, Ohno K, Iwakuma M, Kaneda Y, Saji M. Synaptotagmin I hypothalamic knockdown prevents amygdaloid seizure-induced damage of hippocampal neurons but not of entorhinal neurons. Neuroscience research. 2002;44(4):455-65.

48. Kim SE, Kim HN, Yun YJ, Heo SG, Cho J, Kwon MJ, et al. Meta-analysis of genome-wide SNP- and pathway-based associations for facets of neuroticism. Journal of human genetics. 2017;62(10):903-9.

49. Brini M, Calì T, Ottolini D, Carafoli E. Neuronal calcium signaling: function and dysfunction. Cellular and molecular life sciences : CMLS. 2014;71(15):2787-814.

50. Bocciardi R, Giorda R, Marigo V, Zordan P, Montanaro D, Gimelli S, et al. Molecular characterization of a $t(2 ; 6)$ balanced translocation that is associated with a complex phenotype and leads to truncation of the TCBA1 gene. Human mutation. 2005;26(5):426-36.

51. Calboli FC, Tozzi F, Galwey NW, Antoniades A, Mooser V, Preisig M, et al. A genome-wide association study of neuroticism in a population-based sample. PLoS One. 2010;5(7):e11504.

52. Lee JR. Protein tyrosine phosphatase PTPRT as a regulator of synaptic formation and neuronal development. BMB reports. 2015;48(5):249-55. 
53. Weißflog L, Scholz CJ, Jacob CP, Nguyen TT, Zamzow K, Groß-Lesch S, et al. KCNIP4 as a candidate gene for personality disorders and adult ADHD. European neuropsychopharmacology : the journal of the European College of Neuropsychopharmacology. 2013;23(6):436-47.

54. Luo DG, Yang XL. [Zinc ions: an endogenous neuromodulator]. Sheng li ke xue jin zhan [Progress in physiology]. 2001;32(3):204-8.

55. Gromova OA, Torshin IY, Pronin AV, Kilchevsky MA. [Synergistic application of zinc and vitamin C to support memory, attention and the reduction of the risk of the neurological diseases]. Zhurnal nevrologii $i$ psikhiatrii imeni SS Korsakova. 2017;117(7):112-9.

\section{Figures}
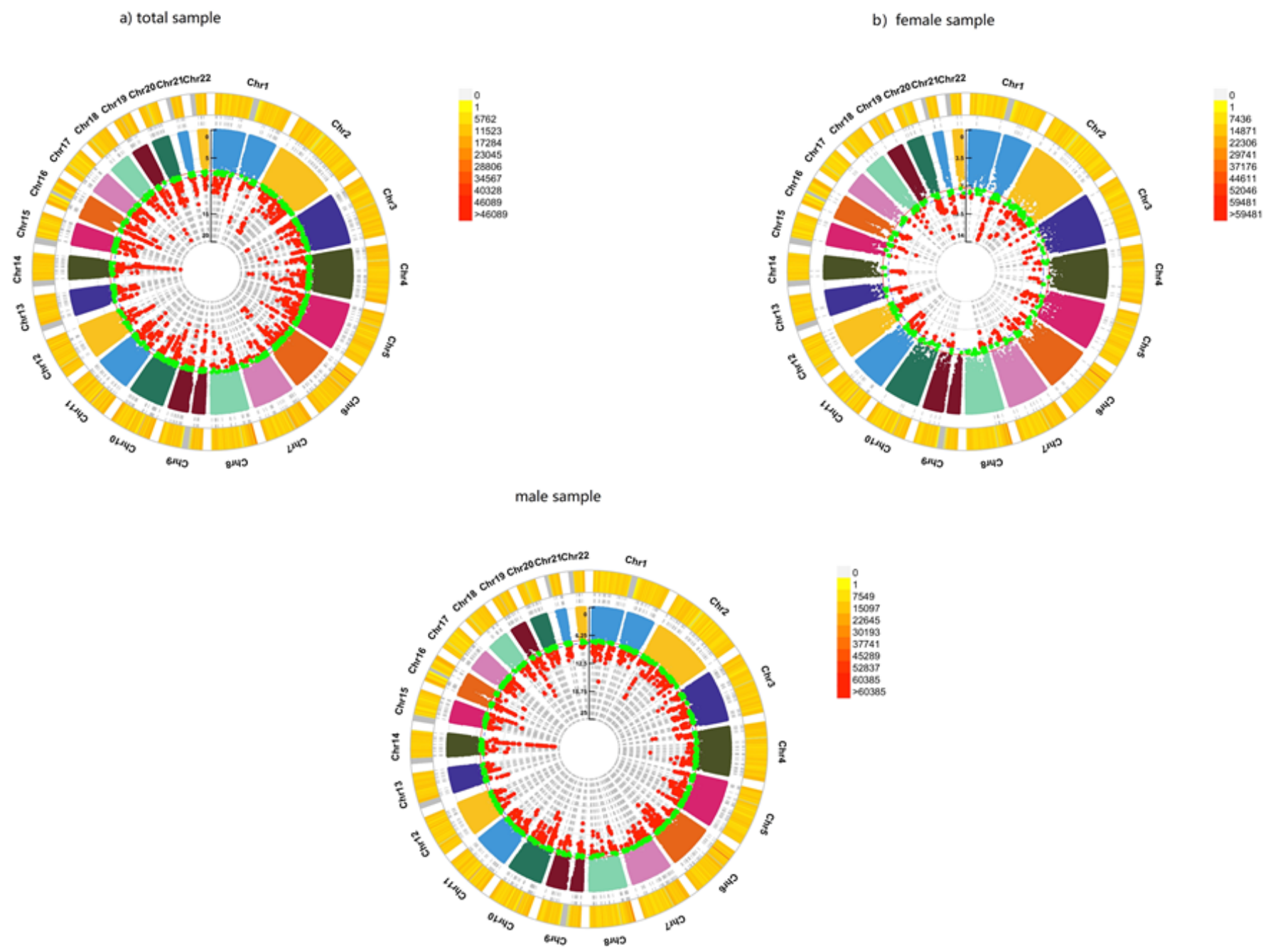

Figure 1 
(a-c) Genomic regions interacting with physical activity for neuroticism Note. From the center, the first circos depicts the $-\log 10$ p-values of each variant due to double exposure, i.e., the effect of both SNP allele and physical activity. The second circos shows chromosome density. Red plots represent the $p<1 \times$ 10-8 and green plots represent $p<5 \times 10-8$. The plots were generated using the "CMplot" R script (https://github.com/YinLiLin/R-CMplot).

\section{Supplementary Files}

This is a list of supplementary files associated with this preprint. Click to download.

- SupplementaryTable16.xlsx 